\title{
BLADE Sequences in Transverse T2-weighted MR Imaging of the Cervical Spine. Cut-off for Artefacts?
}

\section{BLADE-Sequenzen zur transversalen T2-gewichteten MRT der HWS. Ende aller Artefakte?}

Authors

Affiliations
T. Finkenzeller ${ }^{1}$, C. M. Wendl ${ }^{2}$, S. Lenhart ${ }^{3}$, C. Stroszczynski² ${ }^{2}$ G. Schuierer ${ }^{4}$, C. Fellner ${ }^{2}$

Institute of Radiology and Neuroradiology, Hospital Nuremberg Sued, Nuremberg

Institute of Radiology, University Hospital Regensburg

Radiology and Neuroradiology, Klinikum Weiden

Institute of Neuroradiology, Center of Neuroradiology, Regensburg

\author{
Key words \\ - spine \\ - spinal cord \\ - MR-imaging \\ - spinal canal \\ - technical aspects
}

received 20.1.2014

accepted $\quad 12.8 .2014$

Bibliography

Dol http://dx.doi.org/

10.1055/s-0034-1385179

Published online: 22.9.2014

Fortschr Röntgenstr 2015; 187:

102-108 @ Georg Thieme

Verlag KG Stuttgart - New York .

ISSN 1438-9029

\section{Correspondence}

\section{Dr. Thomas Finkenzeller}

Institute of Radiology and Neuroradiology, Klinikum

Nuernberg Sued

Breslauerstraße 201

90471 Nuernberg

Germany

Tel.: ++ 49/911/398117504

Fax: ++ 49/911/3985206

thomas.finkenzeller@

klinikum-nuernberg.de

\section{Zusammenfassung}

v

Ziel: BLADE (PROPELLER) Sequenzen reduzieren Artefakte in der sagittalen Bildgebung der Halswirbelsäule. Diese konnten aber nur eingeschränkt in die axiale Schichtrichtung übertragen werden, da hier bisher vermehrte through plane Artefakte des Liquors den BLADE-Benefit wieder aufgehoben haben. Ziel dieser Studie war es, eine axiale T2-BLADE-Sequenz mit optimierten Untersuchungsparametern mit einer T2-TSE zu vergleichen.

Material und Methoden: Beide Sequenzen wurden bei 58 Patienten mit 31 Bandscheibenschäden, 16 knöchernen und 11 Myelon-Läsionen verglichen. Bildschärfe, Myelonbeurteilbarkeit, Liquorflussartefakte und Läsionserkennbarkeit wurden von 3 unabhängigen Auswertern beurteilt. Zusätzlich wurden die Untersucher gefragt, welche der Sequenzen sie für eine klinisch diagnostische Auswertung bevorzugen würden. Die statistische Auswertung erfolgte mittels Vorzeichen- und $x 2$ - Test.

Ergebnisse: BLADE zeigte signifikant bessere Bildschärfe, Myelonbeurteilbarkeit und allgemeine Läsionserkennbarkeit. BLADE wurde für fast alle Läsionen als besser gewertet, für knöcherne Läsionen war der Unterschied im Vergleich zur T2TSE signifikant. Im Bezug auf Liquorpulsationsartefakte zeigte sich kein statistischer Unterschied der Sequenzen. Im direkten Vergleich bevorzugten alle Auswerter die BLADE-Sequenz.

Schlussfolgerung: Eine axiale T2-BLADE-Sequenz mit optimierten Untersuchungsparametern vermindert das Problem der through-plane Artefakte des Liquors in dieser Orientierung. Sie bietet durch die Reduktion der übrigen Artefakte eine bessere Bildqualität und hat somit das Potential, besonders bei unkooperativen Patienten, die Anzahl nicht auswertbarer Untersuchungen zu minimieren.

\section{Abstract \\ $\nabla$}

Purpose: The BLADE (PROPELLER) technique reduces artefacts in imaging of the cervical spine in sagittal orientation, but till now failed to do so in axial orientation, because here it increased through plane CSF-flow artefacts, which spoiled the benefit of BLADE artefact reduction "in plane". The aim of this study was to compare a BLADE sequence with optimised measurement parameters in axial orientation to T2-TSE.

Materials and Methods: Both sequences were compared in 58 patients with 31 discal, 16 bony and 11 spinal cord lesions. Image sharpness, reliability of spinal cord depiction, CSF flow artefacts and lesion detection were evaluated by 3 independent observers. Additionally the observers were asked which sequence they would prefer for diagnostic workup. Statistical evaluations were performed using sign and $\mathrm{x} 2$ test.

Results: BLADE was significantly superior concerning image sharpness, spinal cord depiction and overall lesion detection. BLADE was rated better for most pathologies, for bony lesions the differences compared with TSE were statistically significant. Regarding CSF-flow artefacts both sequences showed no difference. All readers preferred BLADE in side by side reading.

Conclusion: An optimised axial T2 BLADE sequence decreases the problems of increased through plane CSF-flow artefacts in this orientation. By reducing various other artefacts it yields better image quality and has the potential to reduce the number of non-diagnostic examinations especially in uncooperative patients.

Key points:

- T2 BLADE/PROPELLER sequences proofed to reduce artefacts in sagittal spine imaging

- BLADE/PROPELLER improve image quality, but can aggravate CSF flow artefacts in axial orientation 
Kernaussagen:

- T2-BLADE/PROPELLER-Sequenzen reduzieren Artefakte in sagittaler Orientierung an der Wirbelsäule

- BLADE/PROPELLER verbessern die Bildqualität, können aber Liquorflussartefakte in axialer Orientierung verstärken

- Optimierte Sequenzparameter für axiale T2-BLADE reduzieren erhöhte "through-plane" Artefakte des Liquors

- Optimierte axiale T2-BLADE vermindern nicht-diagnostische Untersuchungen vor allem bei unkooperativen Patienten
- optimised parameter setting for axial T2 BLADE reduces "through-plane" CSF artefacts aggravation

- optimised axial T2 BLADE reduces non-diagnostic examinations especially in uncooperative patients

Citation Format:

- Finkenzeller T, Wendl CM, Lenhart S et al. BLADE Sequences in Transverse T2-weighted MR Imaging of the Cervical Spine. Cut-off for Artefacts?. Fortschr Röntgenstr 2015; 187: 102-108

\section{Introduction}

Magnetic resonance imaging is the method of choice for imaging of the spine and can identify virtually all clinically relevant pathologies, including degenerative and inflammatory, as well as traumatic or neoplastic lesions [1]. Axial T2WI of the spine and spinal cord is prone to a variety of artifacts, especially in the cervical and thoracic region [2]. Different imaging techniques have been developed with the aim of reducing artifacts. One way is to increase the speed of data acquisition by using parallel imaging [3]. Another way is the correction of translational and rotational movement during image acquisition using Periodically ROtated overlapping ParallEL Lines with Enhanced Reconstruction (PROPELLER or BLADE) sequences which have been shown to be beneficial in several studies. The application of this technique improved image quality in the heart [4] and abdominal examinations [5] as well as in head and spine imaging [6-9] by overlapped sampling of the k-space in a rotating manner. In the cervical spine it provided good results in sagittal T2WI [10] by reducing the extent of artefacts. It reduced motion artifacts caused by pulsatile flow of vessels or CSF, swallowing as well as truncation artifacts. Many patients undergoing MRI of the cervical spine are in a clinical condition which makes it difficult for them to cooperate sufficiently, resulting in active patient motion followed by a decline in image quality. Besides pulsatile flow and cross talk artifacts, chemical shift artifacts at the transition between the junction of CSF, dura mater and epidural fat obscure the dura layer in conventional TSE or fast spin echo images. Furthermore, CSF dynamics frequently impair the delineation of subarachnoid spaces due to superimposed flow effects around the spinal cord leading to difficulties in the differentiation between the epidural and subdural space, as well as lesion detection in this compartment.

Recent studies showed that use of the BLADE technique for sagittal T2WI of the cervical spine [10] and for coronal T1WI of head and neck [11] makes it possible to significantly reduce different artifacts. Axial T2-weighted images depict the anatomic structures and signal changes of the cervical spine and spinal cord best, but also have a high sensitivity to artifacts in this orientation. Use of BLADE for axial imaging of the cervical spine in a previous study showed highly increased through-plane CSF-flow artifacts with impaired depiction of structures within the subarachnoid space [12], leading to the authors' conclusion that the use of BLADE for axial orientation could not be generally recommended in this region.

The aim of our study was to evaluate whether a BLADE sequence with an optimized setting of measurement parameters in axial orientation enables reduction or even elimination of CSF-flow artifacts compared to TSE and thereby improves the detection of the spinal cord and spine lesions in the upper spine region. For this purpose we evaluated image sharpness, reliability of spinal cord depiction, CSF-flow artifacts, delineation of the neural foramina and vertebral disc comparing axial T2 TSE with an optimized axial BLADE sequence with identical geometrical parameters.

\section{Methods \\ $\nabla$ \\ Patients}

In this prospective study 58 consecutive patients ( 32 men and 26 women) with an average age of 54 years ( \pm 17 years) (range from 17-86 years), referred for MRI of the cervical spine received T2WI in axial orientation with TSE and BLADE images. The study was approved by the institutional review board.

All patients were referred for workup of miscellaneous neurological symptoms. Findings were judged on the complete clinical MR examination as well as symptoms, medical charts and/or follow-up examinations. For patients with more than one lesion, the reviewers chose the most relevant one with respect to the clinical information available for the patient.

The examinations resulted in 31 discal lesions (disc herniation or protrusion), 16 bony lesions (sponylarthrosis deformans, uncovertebral arthrosis, spinal canal stenosis) and 11 spinal cord lesions (myelopathy and ED lesions).

\section{MR examination}

All images were acquired on a $1.5 \mathrm{~T}$ imager (Magnetom Avanto Siemens, Erlangen, Germany) with a combination of head, neck and spine array coils. The gradient system had a $45 \mathrm{mT} / \mathrm{m} \mathrm{max}-$ imum gradient field strength and a $200 \mathrm{~T} / \mathrm{m}$ / s slew rate.

Axial T2 TSE and BLADE were performed in a randomized order without repetition of sequences even if the image quality was insufficient. After sagittal T2 and T1WI, axial TSE and BLADE sequences were planned over the region most suspicious for the clinical problems of the patient. Both sequences had a slice thickness (SD) of $4 \mathrm{~mm}$ with a slice gap of $10 \%$ and identical geometrical parameters with a field of view (FOV) of $190 \times 190 \mathrm{~mm}$ and matrix size of $320 \times 320$. The TSE sequence with conventional $\mathrm{k}$-space filling was performed in axial orientation with TR $4100 \mathrm{~ms}$ and TE $97 \mathrm{~ms}$ and BLADE with rotating partially overlapping lines k-space filling with TR $3000 \mathrm{~ms}$ and TE $98 \mathrm{~ms}$, respectively. Detailed information about the sequence parameters is given in 0 Table 1.

In addition to the study sequences, sagittal T2 TSE and short TI inversion recovery (STIR) as well as sagittal T1WI without administration of contrast were acquired. In some cases contrast-enhanced T1WI in sagittal and axial orientation was added depending on the pathology revealed. 
Image evaluation

Blinded to imaging technique as well as to patient data, medical history or additional MR images, three independent readers assessed the study criteria. Reader 1 (T.F.) was an experienced neuroradiologist with more than ten years of experience, reader 2 (S. L.) was a resident radiologist with two years of experience in MRI and reader 3 (C.W.) a neuroradiologist with two years of experience in neuro - MRI. All readers evaluated the images qualitatively by judging axial TSE and BLADE in a randomized order, blinded to any information regarding sequence type. Correlation with sagittal T2WI was possible. All readers were allowed to choose optimal window and level settings based on their own judgment. The system they used for grading image quality was on a scale from 1 to 5 (1: excellent, without any impairment of image qual-

Table 1 Measurement parameters for axial T2-weighted TSE and BLADE.

Tab. 1 Messparameter der axialen T2-gewichteten TSE und BLADE-Sequenzen.

\begin{tabular}{|lll|}
\hline & TSE & BLADE \\
\hline TR [ms] / TE [ms] & $4110 / 97$ & $3000 / 98$ \\
\hline echo train length & 17 & 31 \\
\hline bandwidth [Hz/pixel] & 140 & 295 \\
\hline slice thickness [mm] / slice gap [mm] & $4 / 0.4$ & $4 / 0.4$ \\
\hline FOV [mm $\times$ mm] & $190 \times 190$ & $190 \times 190$ \\
\hline matrix size & $320 \times 320$ & $320 \times 320$ \\
\hline phase encoding direction & $\mathrm{A}-\mathrm{P}$ & rotating \\
\hline $\begin{array}{l}\text { oversampling (phase encoding } \\
\text { direction) }\end{array}$ & $40 \%$ & $25 \%$ \\
\hline number of acquisitions & & \\
\hline concatenations & 2 & 1 \\
\hline flow compensation & 1 & 2 \\
\hline acquisition time [min:s] & slice direction & - \\
\hline restore pulse & $3: 48$ & $4: 02$ \\
\hline RF pulse type & yes & yes \\
\hline
\end{tabular}

ity / 2: good, with only minimal impairment of image quality / 3: moderate, showing artifacts which diminish image quality but are still diagnostic / 4: poor, with severe impairment of image quality and limited diagnostic reliability / 5: non-diagnostic, artifacts/alterations are too severe to make a diagnosis). They assessed the following features: Image sharpness, diagnostic reliability of spinal cord depiction, CSF-pulsation artifacts, depiction of neural foramina. Furthermore, delineation of lesions concerning the vertebral disc (disc protrusion or herniation), the bones (as narrowing of the spinal canal or the neural foramina in axial orientation) and the spinal cord (myelopathy or ED lesions) were registered.

In a second session the readers were asked which sequence they would prefer for diagnostic workup of the specific lesion in side by side comparison of axial BLADE and TSE. They also could grade both sequences as being equal.

\section{Statistical analysis}

All statistical calculations and tests were performed using the SPSS software (version 19.0 IBM SPSS Statistics, Armonk, New York, USA). Results of the visual evaluation for TSE and BLADE were compared with the sign test and $X^{2}$ test. P-values $<0.05$ were considered statistically significant.

\section{Results \\ $\nabla$}

P-values of image-based grading of the different criteria evaluated by the three readers are summarized in $\bullet$ Table 2 . In the grading of the individual readers, BLADE was significantly superior $(\mathrm{p}<0.05)$ to TSE regarding image sharpness, diagnostic reliability of spinal cord depiction and overall lesion detection ( $\bullet$ Fig. 1). Regarding the evaluation of disc herniation and lesions of the spinal cord ( $\bullet$ Fig. 2 ), statistical significance was missed, but BLADE was rated better in the majority of cases leading to a highly positive trend in favor of BLADE ( $\bullet$ Table 2 ).

Table 2 Sequence graded as superior (BLADE or TSE) for the different criteria evaluated by three readers including P-values (sign test).

Tab. 2 Wertung der überlegenen Sequenz (BLADE oder TSE) für die einzelnen Kriterien durch die drei Auswerter (mit p-Werten des Vorzeichentests).

\begin{tabular}{|c|c|c|c|c|c|c|c|c|c|}
\hline & reader 1 & & & reader 2 & & & reader 3 & & \\
\hline & $\begin{array}{l}\text { BLADE } \\
\text { superior }\end{array}$ & $\begin{array}{l}\text { TSE } \\
\text { superior }\end{array}$ & p & $\begin{array}{l}\text { BLADE } \\
\text { superior }\end{array}$ & $\begin{array}{l}\text { TSE } \\
\text { superior }\end{array}$ & p & $\begin{array}{l}\text { BLADE } \\
\text { superior }\end{array}$ & $\begin{array}{l}\text { TSE } \\
\text { superior }\end{array}$ & p \\
\hline image sharpness & $\begin{array}{l}41 / 58 \\
71 \%\end{array}$ & $\begin{array}{l}4 / 58 \\
7 \%\end{array}$ & $<0.001$ & $\begin{array}{l}38 / 58 \\
66 \%\end{array}$ & $\begin{array}{l}8 / 58 \\
14 \%\end{array}$ & $<0.001$ & $\begin{array}{l}19 / 58 \\
33 \%\end{array}$ & $\begin{array}{l}5 / 58 \\
9 \%\end{array}$ & 0.007 \\
\hline spinal cord depiction & $\begin{array}{l}33 / 58 \\
57 \%\end{array}$ & $\begin{array}{l}7 / 58 \\
12 \%\end{array}$ & $<0.001$ & $\begin{array}{l}30 / 58 \\
52 \%\end{array}$ & $\begin{array}{l}15 / 58 \\
26 \%\end{array}$ & 0.036 & $\begin{array}{l}22 / 58 \\
38 \%\end{array}$ & $\begin{array}{l}6 / 58 \\
10 \%\end{array}$ & 0.004 \\
\hline CSF artifacts & $\begin{array}{l}8 / 58 \\
14 \%\end{array}$ & $\begin{array}{l}8 / 58 \\
14 \%\end{array}$ & 1.000 & $\begin{array}{l}13 / 58 \\
22 \%\end{array}$ & $\begin{array}{l}12 / 58 \\
20 \%\end{array}$ & 1.000 & $\begin{array}{l}12 / 58 \\
20 \%\end{array}$ & $\begin{array}{l}12 / 58 \\
20 \%\end{array}$ & 1.000 \\
\hline $\begin{array}{l}\text { depiction of } \\
\text { neural foramina }\end{array}$ & $\begin{array}{l}32 / 58 \\
55 \%\end{array}$ & $\begin{array}{l}7 / 58 \\
12 \%\end{array}$ & $<0.001$ & $\begin{array}{l}34 / 58 \\
58 \%\end{array}$ & $\begin{array}{l}6 / 58 \\
10 \%\end{array}$ & $<0.001$ & $\begin{array}{l}13 / 58 \\
22 \%\end{array}$ & $\begin{array}{l}2 / 58 \\
3 \%\end{array}$ & 0.007 \\
\hline lesion depiction & $\begin{array}{l}39 / 58 \\
67 \%\end{array}$ & $\begin{array}{l}6 / 58 \\
10 \%\end{array}$ & $<0.001$ & $\begin{array}{l}39 / 58 \\
67 \%\end{array}$ & $\begin{array}{l}10 / 58 \\
17 \%\end{array}$ & $<0.001$ & $\begin{array}{l}32 / 58 \\
55 \%\end{array}$ & $\begin{array}{l}13 / 58 \\
22 \%\end{array}$ & 0.007 \\
\hline $\begin{array}{l}\text { lesion depiction } \\
\text { disc herniation } \\
\mathrm{n}=31\end{array}$ & $\begin{array}{l}18 / 31 \\
59 \%\end{array}$ & $\begin{array}{l}4 / 31 \\
13 \%\end{array}$ & 0.004 & $\begin{array}{l}17 / 31 \\
55 \%\end{array}$ & $\begin{array}{l}8 / 31 \\
26 \%\end{array}$ & 0.108 & $\begin{array}{l}12 / 31 \\
39 \%\end{array}$ & $\begin{array}{l}9 / 31 \\
29 \%\end{array}$ & 0.664 \\
\hline $\begin{array}{l}\text { lesion depiction } \\
\text { bony lesion } \\
\mathrm{n}=16\end{array}$ & $\begin{array}{l}11 / 16 \\
69 \%\end{array}$ & $\begin{array}{l}1 / 16 \\
6 \%\end{array}$ & $<0.001$ & $\begin{array}{l}12 / 16 \\
75 \%\end{array}$ & $\begin{array}{l}1 / 16 \\
6 \%\end{array}$ & $<0.001$ & $\begin{array}{l}11 / 16 \\
69 \%\end{array}$ & $\begin{array}{l}2 / 16 \\
12 \%\end{array}$ & 0.003 \\
\hline $\begin{array}{l}\text { lesion depiction } \\
\text { spinal cord lesion } \\
n=11\end{array}$ & $\begin{array}{l}9 / 11 \\
82 \%\end{array}$ & $\begin{array}{l}2 / 11 \\
19 \%\end{array}$ & 0.065 & $\begin{array}{l}9 / 11 \\
82 \%\end{array}$ & $\begin{array}{c}2 / 11 \\
19 \%\end{array}$ & 0.065 & $\begin{array}{l}8 / 11 \\
72 \%\end{array}$ & $\begin{array}{c}3 / 11 \\
27 \%\end{array}$ & 0.227 \\
\hline
\end{tabular}



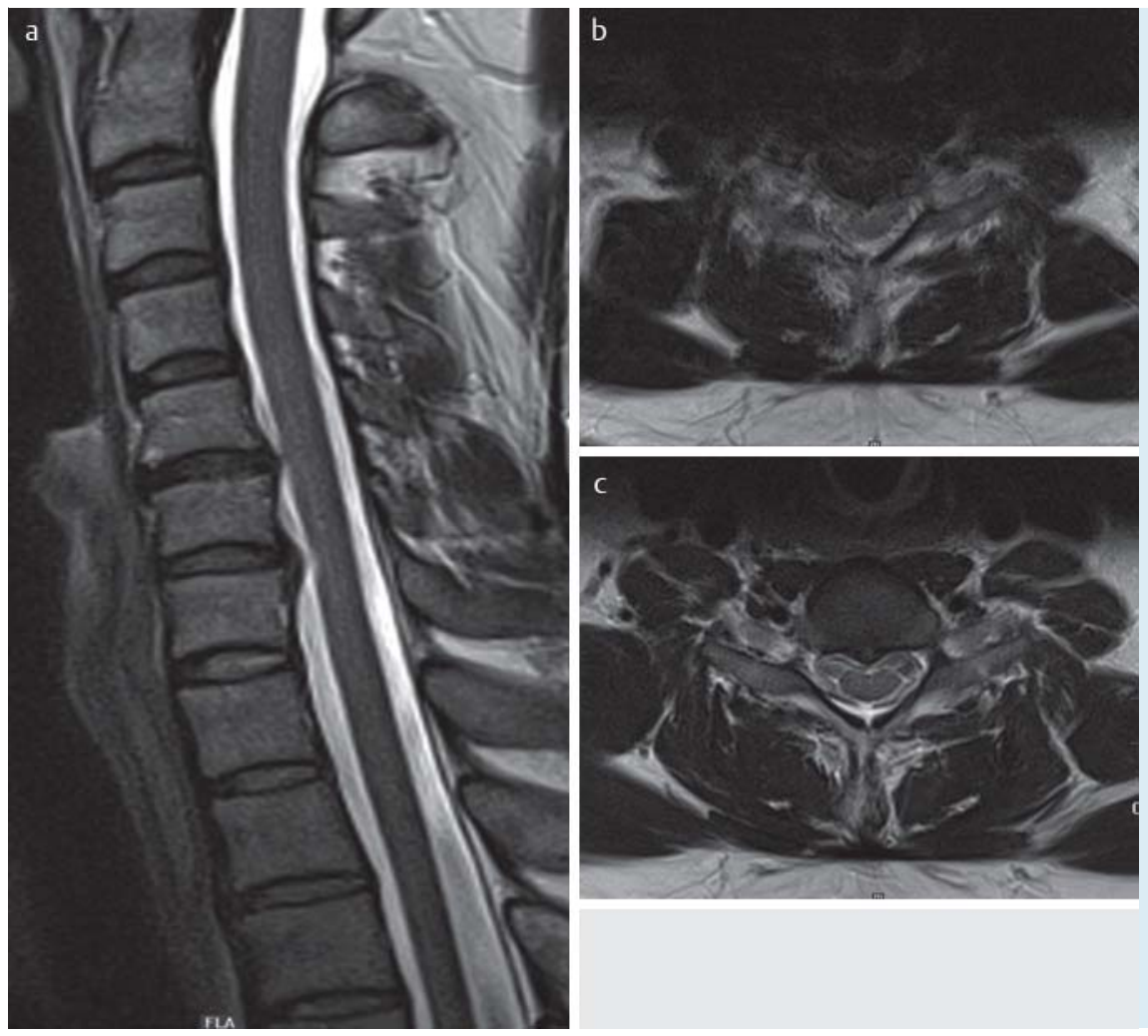

Fig. 1 Sagittal T2 BLADE image a in a non-cooperating patient with degenerative disc disease level C5/6 and C6/7 and marked motion artifacts in axial T2-TSE $\mathbf{b}$ leading to obscuration of anatomic structures at level C6/7. Axial T2 BLADE sequence c shows through-plane flow-related CSF artifacts and median disc protrusion with good delineation of the spinal cord and anatomic structures compared to T2-TSE.

Abb. 1 Sagittale T2-BLADE-Bilder a bei eingeschränkt kooperationsfähigem Patienten mit degenerativen Veränderungen auf Höhe HWK 5/6 und

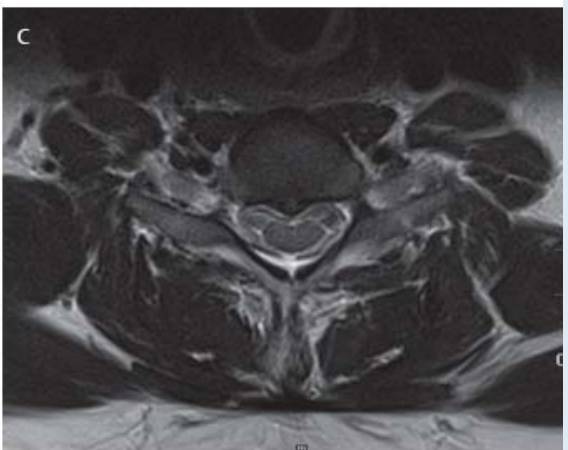
6/7 und ausgeprägten Bewegungsartefakten in den axialen T2-TSE $\mathbf{b}$ Schichten. Diese führen zu schlechter Beurteilbarkeit der anatomischen Strukturen auf Höhe HWK 6/7. Die axiale T2-BLADE-Sequenz c zeigt trotz "Through plane"-Artefakte im Liquor eine mediane Bandscheibenprotrusion sowie eine gute Beurteilbarkeit des Myelons und der umgebenden anatomischen Strukturen im Vergleich zUr T2-TSE.
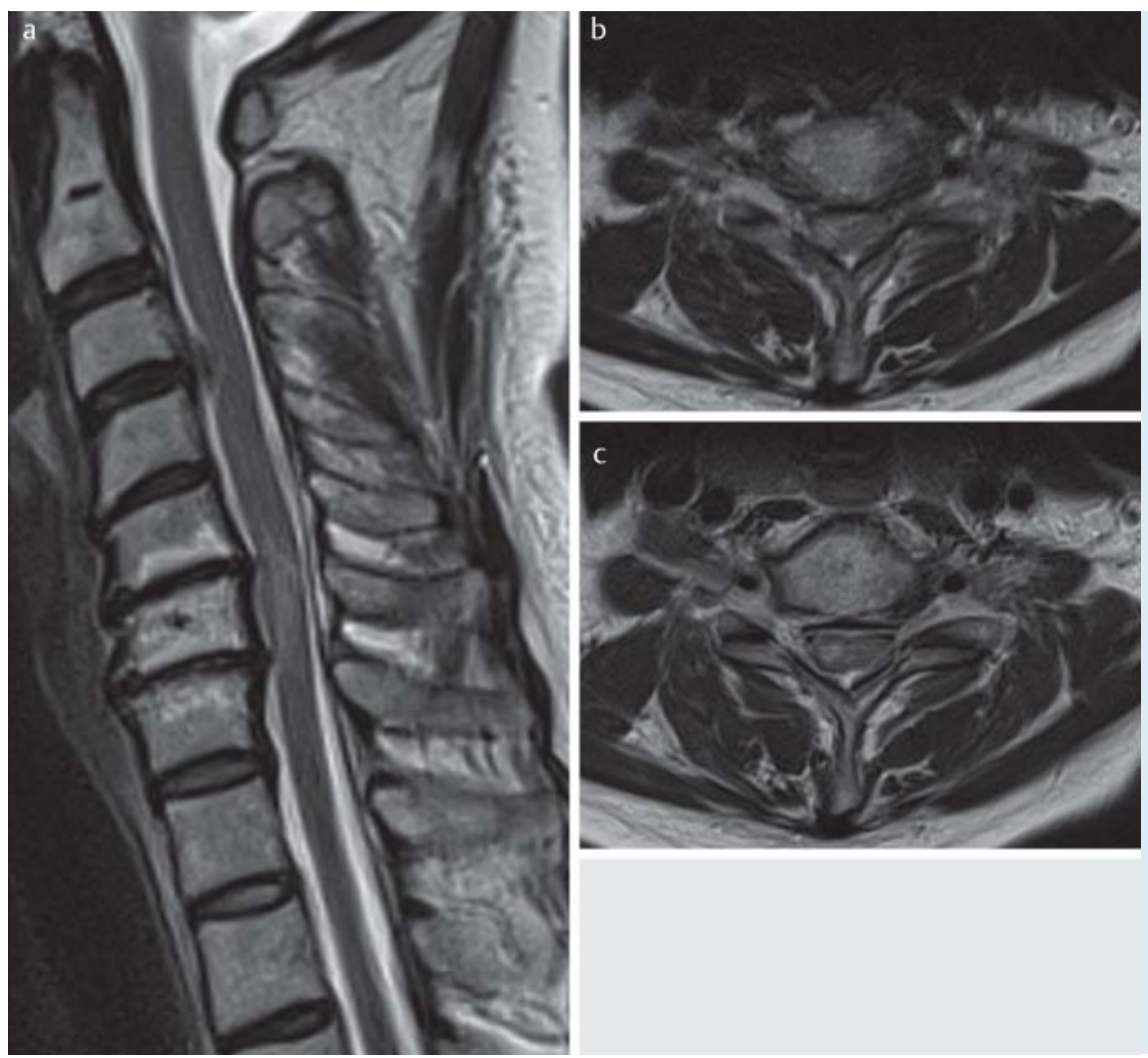

Fig. 2 Osteochondrotic spine pronounced at level C5 to C7 in sagittal T2 BLADE a with artifacts in axial T2 TSE b leading to loss of differentiation between spinal cord and subdural space. Axial T2 BLADE c on the same level clearly depicts the right-sided myelopathic lesion visualized in sagittal T2, but difficult to differentiate in T2 TSE $\mathbf{b}$. Moreover despite spinal canal narrowing at level $\mathrm{C} 6 / 7$, axial BLADE shows remaining CSF around cervical myelon.

Abb.2 Osteochondrotische Veränderungen betont HWK 5 bis 7 in sagittaler T2-BLADE abzu-

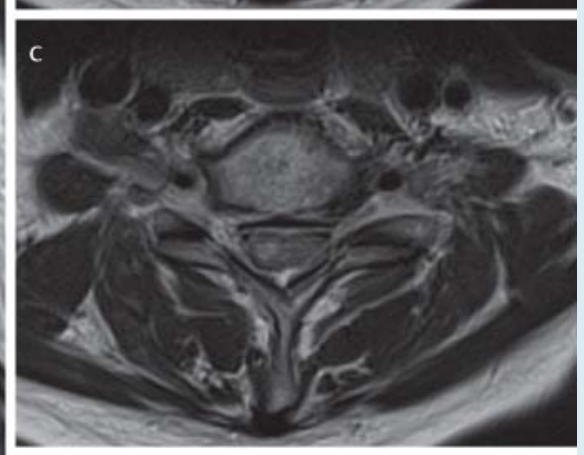
grenzen a mit deutlichen Artefakten in den axialen T2-TSE die die Grenzen zwischen Myelon und Subdural-/Subarachnoidalraum obskurieren. Axiale T2-BLADE-Bilder $\mathbf{c}$ auf derselben Höhe zeigen deutlich eine rechtsseitige Myelopathie die bereits auf den sagittalen Schichten zu sehen war, aber in T2TSE nicht verifiziert werden konnte. Darüber hinaus zeigen die axialen BLADE-Schichten trotz der spinalen Enge auf Höhe HWK 6/7 noch gering verblieben Liquorsaum.

Superimposed artifacts ( $\mathbf{F i g} . \mathbf{3}$ ) in the subdural/subarachnoid space related to CSF-flow effects occurred at a similar extent in BLADE and TSE ( $\bullet$ Table 2 ) leading to nearly identical values without any preference for one sequence $(p=1.0)$.
Differentiation between intra-foraminal nerve root and surrounding fatty tissue was easier in BLADE than TSE leading to a preference for BLADE in $22-58 \%$ of the cases, whereas TSE was only favored in $3-12 \%$ ( $\bullet$ Fig. 1, 2). 

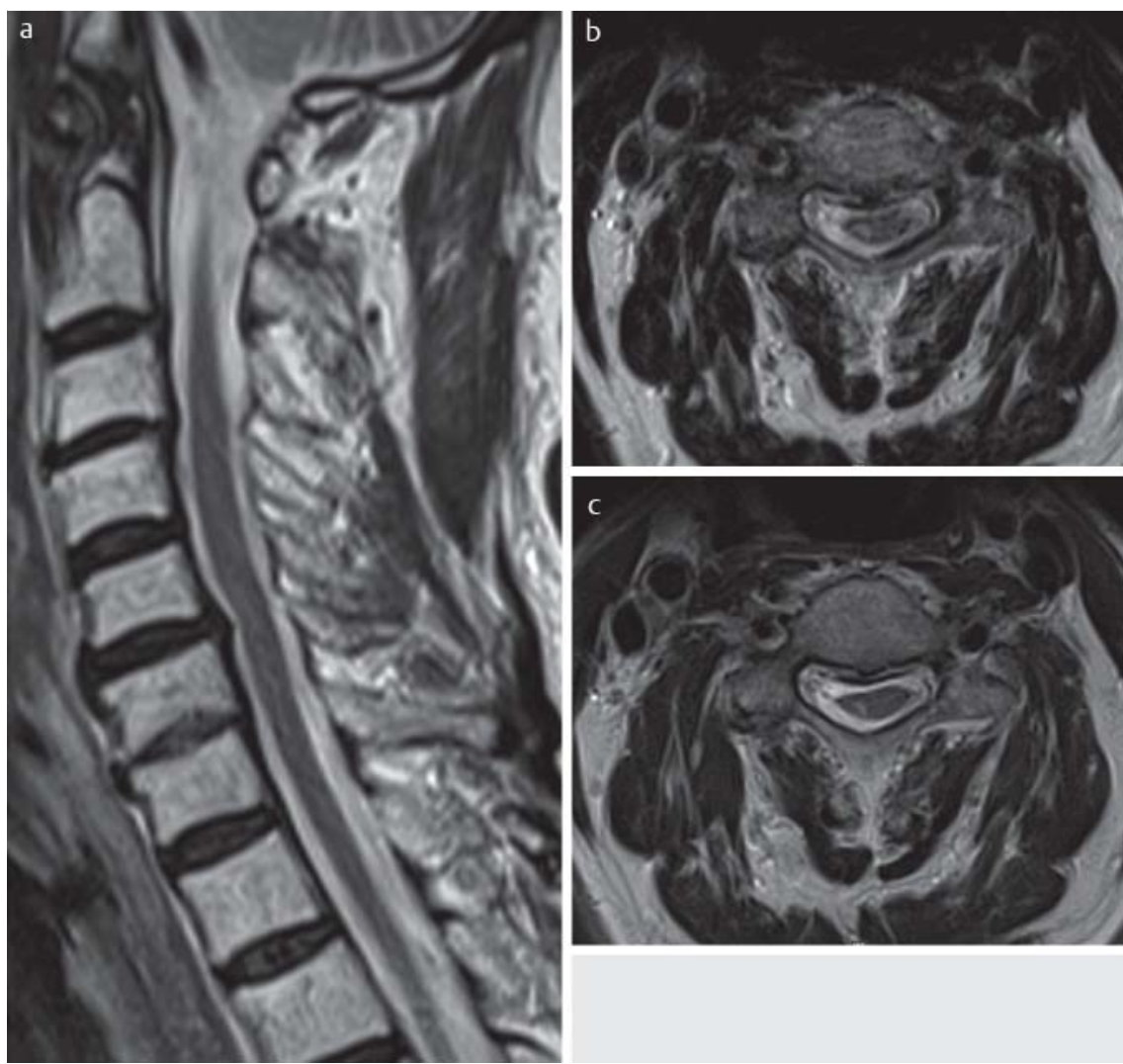

Fig. 3 Disc protrusion in sagittal T2 BLADE a with corresponding axial images at level $\mathrm{C} 5 / 6$. In axial T2 TSE $\mathbf{b}$ differentiation between spinal cord and subdural CSF is difficult. Flow-related CSF artifacts as well as motion artifacts obscure anatomic boundaries in this sequence type, whereas axial BLADE c depicts the spinal cord and its transition to CSF space with higher confidence. Additionally, lateral recesses show only minor flow-related CSF changes in BLADE c.

Abb.3 Bandscheibenprotrusion in der sagittalen T2-BLADE a mit den jeweils korrespondierenden axialen Bildern auf Höhe HWK 5/6. In den axialen T2-TSE b Bildern ist die Abgrenzung zwischen Mye-

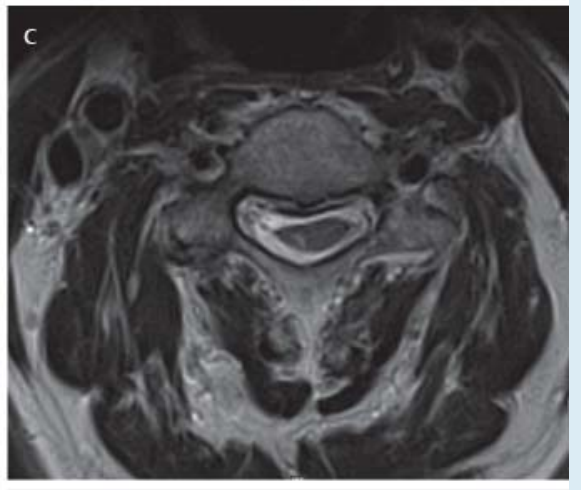
lon und Liquor nur schwierig möglich. Flussassoziierte Liquorartefakte und Bewegungsartefakte verwischen bei dieser Sequenzwahl die anatomischen Grenzen, wohingegen die axiale T2-BLADE c das Myelon und seine Abgrenzung zum Liquor deutlicher und klarer zeigt. Zusätzlich sieht man auch weniger flussbedingte Liquorartefakte in den lateralen Abschnitten, Richtung Neuroforamen.

\begin{tabular}{|c|c|c|c|c|c|}
\hline grade & criterion & & reader 1 & reader 2 & reader 3 \\
\hline \multirow[t]{8}{*}{5} & \multirow{2}{*}{ image sharpness } & TSE & 2 & 1 & 3 \\
\hline & & BLADE & 0 & 0 & 0 \\
\hline & \multirow[t]{2}{*}{ spinal cord depiction } & TSE & 2 & 1 & 2 \\
\hline & & BLADE & 0 & 0 & 0 \\
\hline & \multirow[t]{2}{*}{ CSF flow } & TSE & 2 & 1 & 1 \\
\hline & & BLADE & 0 & 1 & 0 \\
\hline & \multirow[t]{2}{*}{ lesion depiction } & TSE & 1 & 4 & 3 \\
\hline & & BLADE & 0 & 0 & 0 \\
\hline \multirow[t]{8}{*}{4} & \multirow[t]{2}{*}{ image sharpness } & TSE & 12 & 7 & 8 \\
\hline & & BLADE & 0 & 0 & 1 \\
\hline & \multirow[t]{2}{*}{ spinal cord depiction } & TSE & 11 & 12 & 6 \\
\hline & & BLADE & 0 & 0 & 1 \\
\hline & \multirow[t]{2}{*}{ CSF flow } & TSE & 11 & 10 & 5 \\
\hline & & BLADE & 8 & 7 & 1 \\
\hline & \multirow[t]{2}{*}{ lesion depiction } & TSE & 17 & 9 & 6 \\
\hline & & BLADE & 3 & 2 & 1 \\
\hline
\end{tabular}

Table 3 Number of examinations rated as grade 5 (non-diagnostic) or 4 (poor, with limited diagnostic reliability) for the different criteria and readers.

Tab. 3 Anzahl der Untersuchungen gewertet als Grad 5 (nicht diagnostisch) oder Grad 4 (schlechte Qualität, mit eingeschränkter diagnostischer Wertigkeit) für die unterschiedlichen Kriterien und Auswerter.

With regard to lesion detection, evaluation was subdivided into three major "pathologies" responsible for the patients' clinical presentation. Disc herniation $(n=31)$ and spinal cord lesions $(n=11)$ showed a superiority of BLADE imaging without significance but with rather high percentages (disc herniation: $39-$ 59\%; spinal cord lesions: 72 - $82 \%$ ) compared to TSE (disc herniation: $13-29 \%$; spinal cord lesions: $19-27 \%$ ). The bony lesions $(n=16)$ were better visualized with BLADE in $69-75 \%$ of all cases resulting in a statistically significant difference of BLADE compared with TSE.

- Table 3 shows a comparison of how often BLADE or TSE was graded as not diagnostic (grade 5) or with limited diagnostic reliability (grade 4). Regarding all evaluated criteria, BLADE was rated as non-diagnostic (for CSF-flow artifacts) only once, whereas the readers graded up to 9 TSE examinations as non-diagnostic (grade 5 ). Furthermore, the number of images with limited diagnostic reliability (grade 4) was considerably higher for TSE ( $\bullet$ Table 3 ).

In a second part of the visual evaluation, each reader compared BLADE and TSE side by side and stated which of them he would prefer for clinical imaging or if he would grade both as equal. BLADE was preferred in 39/38/28 (reader 1 / reader 2 / reader 3 ) of 58 patients, whereas TSE was favored only in $5 / 9 / 10$ patients in direct comparison. In 14/11/20 patients both were rated as equal, resulting in a significant superiority $(\mathrm{p}<0.001 / \mathrm{p}<0.001 / \mathrm{p}=0.016)$ of BLADE in this section of the evaluation for all readers. 


\section{Discussion}

\section{V}

T2WI of the cervical spine is well established and gives a good overview of the region and its anatomic structures. Sufficient T2 contrast is required to visualize the spinal cord, CSF, bony structures, neural foramen, vertebral disc as well as possible pathologies. In the daily routine the largest portion of examinations deals with degenerative disorders of the spine, but - sometimes clinically more important - abnormalities of the spinal cord (inflammation, myelopathy, edema) are detected and judged at least by their signal in T2-weighted images [1]. As the cervical region is prone to a large variety of artifacts like pulsation, swallowing and involuntary patient movement, reduction of these problems is a major objective in modern spine imaging. In recent studies the application of PROPELLER/BLADE sequences showed a marked reduction of voluntary and involuntary artifacts throughout the body [9-14]. In sagittal cervical spine imaging, it showed improved spinal cord/CSF contrast in BLADE [9] as well as diminished CSF-flow artifacts [12]. It improved the overall image quality and depiction of spinal lesions as well as the depiction of surrounding structures in sagittal orientation [10]. With regard to lesion detection, the diagnostic reliability of spinal cord depiction and the reduction of artifacts are of paramount clinical importance. BLADE proved its benefits in sagittal orientation in the cervical as well as in the lumbar region $[9,10]$. Its application was furthermore beneficial in axial orientation in the lumbar spine [9]. However, in previous studies of the cervical spine, the use of rotating k-space coverage in the PROPELLER/ BLADE technique with its repeated measurement of the central $\mathrm{k}$-space area resulted in a remarkable increase in CSF-flow artifacts in axial orientation [12]. This is because these sequences are able to compensate "in-plane" motion but not "out-of-plane" or "through-plane" movement such as CSF-flow in sagittal direction in axial plane (which is much less pronounced in the lumbar region compared to cervical or thoracic levels). At least, in the cervical region T2-BLADE in axial orientation led to blurring of the subarachnoid space due to superimposed CSF flow effects and thereby degraded results in the evaluation of this area compared to TSE. Nevertheless, for spinal cord depiction axial BLADE was better than TSE but without significance in the cervical spine [12].

Normal CSF shows low signal intensity on T1WI and high signal intensity on T2WI. Depending on various factors (e.g. pulsation of heart and vessels, breathing, width of the spinal canal, examined region) however, the CSF signal is altered by flow phenomena which result in a mostly dark signal on T2 which can significantly compromise image interpretation [15]. In the upper cervical spine CSF flow rates can reach up to $40 \%$ of rates seen in the internal carotid arteries [16] causing significant motion-related alterations in CSF signal. These effects are more pronounced the faster the flow, the thinner the slices and the longer TE. Furthermore, they are maximized in the image plane perpendicular to the flow and for these reasons are mostly seen in the axial plane with predominance in the cervical and thoracic spine [15]. There are different strategies to reduce CSF artifacts including techniques to reduce time of flight and flow-related enhancement effects as well as increased numbers of excitations (prolonging scan time) or swapping of the phase and frequency encoding directions [17].

In this study, we compared T2 BLADE imaging of the cervical spine in axial orientation with our optimized T2 TSE and found that BLADE with appropriate selection of measurement param- eters did improve image quality and lesion depiction without aggravation of CSF-flow artifacts seen in previous studies. Prior to patient examination, we conducted a pilot study with 4 different BLADE sequences on 15 healthy volunteers to find an optimized axial T2 BLADE by modification of different parameters including ETL, number of concatenations (1 or 2), through-plane flow compensation, and BLADE coverage. Geometric parameters were matched in BLADE and TSE to facilitate the comparability of both sequences. Sequence-specific parameters like read out bandwidth were not modified. High BW and long ETL are mandatory for sufficient and fast coverage of the k-space center in BLADE. Acquisition of TSE with a similar bandwidth as BLADE would significantly reduce the SNR (signal-to-noise-ratio) or on the other hand marked increase in acquisition time would be necessary to maintain a sufficient SNR. Using a fixed BW and ETL, BLADE was adjusted to reach a similar TE as in the TSE sequence.

The application of two concatenations was chosen for two reasons: First the use of only one concatenation in the pilot study with healthy volunteers resulted in inferior image quality compared to the application of two. Second, a minimal TR (or otherwise a maximum number of slices for a given TR) cannot be realized with BLADE due to a relatively high specific absorption rate. In our pilot study we evaluated different strategies to improve image quality and artifact reduction. Application of flow compensation in slice direction showed no improvement, while increased BLADE coverage in the different study sequences did significantly improve image quality. We evaluated BLADE coverages from $118.2 \%$ to $185.7 \%$ with the best image quality at $185.7 \%$, which we used for further evaluation in the patient study. After modification and sequence optimization in the axial plane ( $\bullet$ Table 1), the disadvantage of increased CSF-flow artifacts by through-plane motion could be reduced without alteration of the remaining BLADE-specific advantages. In contrast to the results of Ragoschke et al. [12], we did not find an increased obscuration of subdural space by CSF-flow artifacts in regions of spinal canal stenosis or vertebral disc protrusions with the sequences used in this study. CSF flow artifacts were similar or even sometimes reduced compared to T2 TSE. Together with better depiction of the spinal cord, vertebral discs and surrounding tissue, BLADE enabled improved visualization of the subdural/ subarachnoid and epidural space resulting in far fewer images rated as "non-diagnostic" or of "poor quality".

All three readers preferred BLADE for axial T2 imaging of the cervical spine in the majority of cases - similar to previous studies concerning sagittal T2 BLADE [10-12]. Rotating k-space sampling works for uncooperative patients in which case BLADE eliminates patient movement artifacts as well as for cooperative individuals in which case it erases pulsation, Gibbs and susceptibility artifacts $[10,13]$ in plane. As we could optimize sequence parameters for axial BLADE, they did not show increased CSFflow artifacts through-plane, which spoiled the benefits of this sequence type (reduced overall artifacts and better image quality) in previous studies [12]. Therefore, axial T2 BLADE in this application can be recommended even for the delineation of subarachnoid pathologies at least with a $1.5 \mathrm{~T}$ scanner.

However, as shown in previous investigations, the use of sequences with rotating $\mathrm{k}$-space sampling results in better SNR values in bone marrow, vertebral discs, neural roots and fatty tissue $[9,10]$ easing the differentiation of pathological conditions. This is mostly attributed to the significant reduction in motion and flow artifacts compared to conventional k-space sampling sequences. 
The disadvantage of the sometimes longer acquisition time of BLADE sequences is overcome in the daily routine because repetition of sequences becomes unnecessary in many cases. By using BLADE sequences, patient comfort can be enhanced and overall examination time can be shortened while yielding better image quality. In our study the readers graded $2 / 1 / 3$ of the TSE examinations as non-diagnostic (grade 5 ) for overall image sharpness and $1 / 4 / 3$ for lesion depiction, while none of the BLADE sequences received this grading. Only 1 BLADE received grade 5 for CSFflow artifacts as well as TSE in this patient ( Table 3 ). With regard to grade 4 ratings (poor image quality with limited diagnostic reliability), BLADE performed much better than TSE.

We would therefore recommend the clinical use of axial BLADE, especially in uncooperative patients, but even see the potential to replace TSE in standard imaging protocols at least for the described $1.5 \mathrm{~T}$ system. We share the expectation as previously stated by Lavdas et al. [9] that the use of BLADE/PROPELLER sequences in the thoracic spine will be of substantial value in the reduction of several motion artifacts including breathing, cardiac pulsation and CSF flow.

Visual assessment of BLADE and TSE was done by three readers having rather different experience in MRI. Reader 1 was an experienced neuroradiologist, reader 2 was a radiological resident with two years of experience in MRI and reader 3 was a resident with two years of experience in neuro-MRI. Nevertheless, their independent image evaluation gave similar results for all criteria in favor of the BLADE technique ( $\bullet$ Table 2 and 3 ) showing that axial T2-weighted BLADE imaging of the cervical spine is a reliable and robust technique independent of the interpreter's experience.

There are several limitations of the study despite its prospective design: The number of lesions within the spinal cord is rather small and includes no neoplastic or hemorrhagic lesions. Therefore, the diagnostic value of axial T2 BLADE has to be confirmed in a larger variety and number of lesions and patients need to approve its status as a real contender to standard T2 TSE. For this reason, whenever applicable, we would recommend performing axial T2 BLADE adjunctive to an optimized T2 TSE to make it comparable for different pathologies, to learn about its performance on user-specific scanners and to evaluate its potential as a real competitor to optimized axial T2 TSE.

The results reported in this study represent the findings on one specific type of MR scanner with its specific hardware and software. Scanners of different producers or with higher or lower field strengths as well as vendor specific implementations of these sequences (e.g. PROPELLER, MULTIVANE) might yield different results. Therefore, the results of this study should be validated on the specific scanner before use.

\section{Conclusion}

$\nabla$

Sagittal T2-weighted imaging of the cervical spine has proven to benefit from the use of BLADE/PROPELLER sequences, while in axial orientation the subdural space was blurred by pronounced CSF-flow artifacts. An optimized parameter setting of the axial T2 BLADE sequence decreases this problem of increased throughplane CSF-flow artifacts. It yields better overall image quality and lesion detection and CSF visualization is at least equivalent to TSE. Therefore, BLADE reduces the number of non-diagnostic examinations. Thus, we would recommend applying the optimized axial T2-weighted BLADE sequences for imaging of the cervical spine at least in patients not able to cooperate sufficiently. It might even have the potential to replace axial T2 TSE in routine protocols of cervical spine imaging in the future.

\section{Abbreviations \\ PROPELLER Periodically Rotated Overlapping ParallEL Lines with Enhanced Reconstruction \\ CSF cerebrospinal fluid \\ ED encephalomyelitis disseminata \\ HASTE half Fourier acquired single shot turbo spin echo \\ ETL echo train length \\ BW bandwidth \\ T1WI T1-weighted imaging \\ T2WI T2-weighted imaging}

\section{References}

1 Meindl T, Wirth S, Weckebach $S$ et al. Magnetic resonance imaging of the cervical spine: comparison of 2D T2-weighted turbo spin echo, 2D $\mathrm{T} 2{ }^{*}$ weighted gradient-recalled echo and 3D T2-weighted variable flipangle turbo spin echo sequences. Eur Radiol 2009; 19: 713-721

2 Melhem ER. Technical challenges in MR imaging of the cervical spine and cord. Magn Reson Imaging Clin N Am 2000; 8: 435-452

3 Noebauer-Huhmann IM, Glaser C, Dietrich $O$ et al. MR imaging of the cervical spine: assessment of image quality with parallel imaging compared to non-accelerated MR measurements. Eur Radiol 2007; 17 (5): $1147-1155$

4 Pipe JG. Motion correction with PROPELLER MRI: application to head motion and free-breathing cardiac imaging. Magn Reson Med 1999; 42: $963-969$

5 Hirokawa $Y$, Isoda $\mathrm{H}$, Maetani YS et al. MRI artifact reduction and quality improvement in the upper abdomen with PROPELLER and prospective acquisition correction (PACE) technique. Am J Roentgenol 2008; 191: $1154-1158$

6 Wintersperger BJ, Runge VM, Biswas J et al. Brain magnetic resonance imaging at 3 tesla using BLADE compared with standard rectilinear data sampling. Invest Radiol 2006; 41: 586-592

7 Forbes KP, Pipe JG, Karis JP et al. E Brain imaging in the unsedated pediatric patient: Comparison of periodically rotated overlapping parallel lines with enhanced reconstruction with single shot fast spin-echo sequences. AJNR Am J Neuroradiol 2003; 24: 794-798

8 Heyer CM, Lemburg SP, Sterl S et al. Dispensing with Sedation in Pediatric MR Imaging of the Brain: What is Feasible? Fortschr Röntgenstr 2012; 184: 1034-1042

9 Lavdas E, Mavroidis P, Kostopoulos S et al. Elimination of motion, pulsatile flow and cross-talk artifacts using blade sequences in lumbar spine MR imaging. Magn Reson Imaging 2013; 31: $882-890$

10 Fellner C, Menzel C, Fellner FA et al. BLADE in sagittal T2-weighted MR imaging of the cervical spine. Am J Neuroradiol 2010; 31: 674-681

11 Finkenzeller T, Zorger N, Kühnel T et al. Novel application of T1-weighted BLADE sequences with fat suppression compared to TSE in contrast enhanced T1-weighted imaging of the neck: cutting-edge images? Magn Reson Imaging 2013; 37: 660-668

12 Ragoschke-Schumm A, Schmidt P, Schumm J et al. Decreased CSF-flow artifacts in T2 imaging of the cervical spine with periodically rotated overlapping parallel lines with enhanced reconstruction (PROPELLER/ BLADE). Neuroradiology 2011; 53: 13-18

13 Lavdas E, Mavroidis P, Kostopoulos $S$ et al. Improvement of image quality using BLADE sequences in brain MR imaging. Magn Reson Imaging 2013; 31: 189-200

14 Phalke VV, Gujar S, Quint DJ. Comparison of 3.0 T versus 1.5 T MR: imaging of the spine. Neuroimaging Clin N Am 2006; 16: 241 -248

15 Lisanti C, Carlin C, Banks K et al. Normal MRI Appearance and MotionRelated Phenomena of CSF. Am J Roentgenol 2007; 188: 716 - 725

16 Baledent 0 , Henry-Feugeas MC, Idy-Peretti I. Cerebrospinal fluid dynamics and relation with blood flow: a magnetic resonance study with semi-automated cerebrospinal fluid segmentation. Invest Radiol 2001; 36: $368-377$

17 Vargas MI, Delavelle J, Kohler $R$ et al. Brain and spine MRI artifacts at 3 Tesla. J of Neuroradiology 2007; 36: 74-81 